\title{
Risk Factors Associated with Mother-to-Child Transmission of HIV in Dar es Salaam, Tanzania
}

\author{
Felix Elias $^{1 *}$, Nyimvua Shaban ${ }^{1}$ and Edwin Rutalebwa ${ }^{2}$ \\ ${ }^{1}$ Department of Mathematics, University of Dar es Salaam, P.O. Box 35062, Dar es Salaam, \\ Tanzania. \\ ${ }^{2}$ Department of General Study, Dar es Salaam Institute of Technology, P.O. Box 2958, Dar es \\ Salaam, Tanzania. \\ E-mail addresses: shaban.nyimvua@udsm.ac.tz,erutalebwa@gmail.com \\ *Corresponding author: felias77@gmail.com
}

Received 19 May 2021, Revised 15 Dec 2021, Accepted 20 Dec 2021, Published Dec 2021

DOI: https://dx.doi.org/10.4314/tjs.v47i5.24

\begin{abstract}
Despite Tanzania's efforts and substantial progress in PMTCT, about $11 \%$ new infections were recorded among Tanzanian children in 2019 (UNAIDS 2020a). The objective of this study was to determine the rate of HIV transmission and to identify its risk factors among HIV exposed infants born to HIV-positive mothers in Dar es Salaam, Tanzania. A cross-sectional study was conducted using retrospective data collected from HIV-positive mothers and their exposed babies who were followed and registered in health facilities in four administrative districts (Ilala, Temeke, Kinondoni, and Ubungo) in Dar es Salaam between January 2016 and December 2019. To identify risk factors for MTCT, univariate and multivariate Cox Proportional hazard regression analyses were employed. Out of 18705 registered children exposed to HIV, 586 (3.1\%) were positive during the study period, while 18119 (96.9\%) were negative. In this study, the following factors were increasing the risks of MTCT of HIV infections, not receiving ARV prophylaxis right at birth (aHR $=2.39,95 \% \mathrm{CI}: 1.75-3.26, P<0.001)$, unsuppressed maternal viral load $(\mathrm{aHR}=6.26,95 \% \mathrm{CI}: 4.91-7.97, P<0.001)$, WHO clinical stage $3-4(\mathrm{aHR}=1.79$, 95\% CI: $1.44-2.23, P<0.001)$, and mixed feeding (aHR $=4.09,95 \%$ CI: $1.80-9.31, P<0.001)$. The factors maternal age group $25-34$ years $(\mathrm{aHR}=0.47,95 \% \mathrm{CI}: 0.29-0.75, P<0.001)$, being married/cohabiting $(\mathrm{aHR}=0.47,95 \% \mathrm{CI}: 0.23-0.95, P=0.036)$, duration on ART for $>12$ months (aHR $=0.55,95 \%$ CI: $0.45-0.67, P<0.001)$, dried blood spot (DBS) tested at 6 weeks $(\mathrm{aHR}=0.09,95 \%$ CI: $0.04-0.18, P<0.001)$, and exclusive replacement feeding $(\mathrm{ERF})(\mathrm{aHR}=$ 0.32 , 95\% CI: $0.17-0.60, P<0.001)$ decreased the risk of MTCT of HIV infections. These findings indicated that further work is required to scale up PMTCT approaches to concentrate on viral load suppression, taking ARV prophylaxis immediately at birth, and EBF practice in the first 6 months of life.
\end{abstract}

Keywords: HIV, PMTCT, risk factors, mother-to-child transmission (MTCT).

\section{Introduction}

The Human Immunodeficiency Virus (HIV) remains a major global public health concern, having claimed the lives of more than 35.6 million individuals to date (UNAIDS 2020b). In 2019, roughly 38 million individuals worldwide were living with HIV, with 1.7 million individuals being infected for the first time (UNAIDS 2020b). With 20.7 million HIV-positive people in 2019, Eastern and Southern Africa are the world's most affected regions, accounting for more than half of all new HIV infections (UNAIDS 2020b). More than $90 \%$ of HIV 1779 
infections in children under the age of five years are transmitted from mother-to-child transmission (MTCT) or vertically. HIV MTCT remains a major issue, especially in Sub-Saharan Africa, denying children the chance to live a life free of the virus (De Cock et al. 2000). The World Health Organization (WHO) has established a global strategy for preventing mother-to-child transmissions that can reduce the incidence of MTCT to less than 5\% (Chikhungu 2016). Furthermore, the WHO in 2016 published the most recent consolidated recommendations on the use of antiretrovirals for treating and preventing HIV infections, which strongly indicates that all pregnant and breastfeeding women living with HIV, regardless of clinical staging or CD4 cell count, should receive ART treatment for the rest of their lives. It was reported that about $15-45 \%$ of HIV-infected mothers will transmit infections to their unborn children, 5-10\% during pregnancy, $10-15 \%$ during labor and delivery, and 5$20 \%$ during breastfeeding (De Cock et al. 2000). Risks of MTCT of HIV can be decreased to less than $5 \%$ in breastfeeding populations from a background risk of $35 \%$ and to less than $2 \%$ in non-breastfeeding populations from a background risk of $25 \%$ with systematic interventions (WHO 2016). The MTCT of HIV have been confirmed to be below $2 \%$ in many developed countries with these prevention services. These countries' progress was fueled in part by their efforts to ensure that women had early access to prenatal care, HIV testing with their partners, treatment for positive women, and treatment for their babies if they were infected (Sidibé and Singh 2016). Also, various combinations of highly active antiretroviral therapies (HAART), infant formula feeding, and elective caesarean sections have all contributed to this low degree (Giaquinto et al. 2006). There are large differences in national prevalence rates among African countries (UNAIDS 2018). According to the report (Newell 2001), the disparity in risks between regions is primarily due to the characteristics of the population studied in terms of HIV infections and the prevalence of factors affecting the probability of transmission. Breastfeeding's added risks account for a significant portion of the estimated differences (Newell 2001). By 2019, 1.7 million Tanzanians had been diagnosed with HIV. About 77,000 people were newly infected with HIV in the same year, and 27,000 people died of AIDS-related diseases (UNAIDS 2020b). However, the magnitudes of the epidemic vary by regions in Tanzania, ranging from less than $1 \%$ in Zanzibar, $4.9 \%$ in Dar es Salaam, and $11.4 \%$ in Njombe (Ministry of Health, Community Development, Gender, Elderly and Children (MoHCDEC) 2019). Women have a higher prevalence than men $(6.2 \%$ versus $3.7 \%)$ (UNICEF 2020). Tanzania launched the prevention of mother-to-child transmission (PMTCT) programme in 2000, and by 2011, approximately $75 \%$ of all HIV-positive pregnant women in need of ARV therapy had received their doses. Standard antiretroviral care for both the mother and the baby has been incorporated into standard reproductive health programmes to avoid MTCT (UNAIDS 2013). In Tanzania, by 2019, more than $92 \%$ of HIV-positive pregnant women were on successful antiretroviral therapy (ART), and $46.6 \%$ of babies were diagnosed with HIV at birth (UNAIDS 2020b). Without control steps, MTCT rates in Tanzania increase from $3.6 \%$ at six weeks to more than $7 \%$ by the end of breastfeeding (UNICEF 2019). Buchanan et al. (2014) found MTCT prevalence rates of $6.3 \%$ in three northern Tanzanian regions (Arusha, Kilimanjaro, and Tanga). Furthermore, regardless of PMTCT intervention use, the prevalence rate in the Lake Victoria Zone (Mwanza, Tarime, Kagera, and Shinyanga) was $6.1 \%$ (Mirambo et al. 2015).

Despite Tanzania's efforts and substantial progress in PMTCT, about $11 \%$ of new infections were recorded among Tanzanian children in 2019 (UNAIDS 2020a). Poor retention rates among pregnant and lactating mothers $(67 \%$ and $83 \%$, respectively) persist, prompting an $11 \%$ mother-to-child HIV contamination rate in 2019 , compared with a worldwide objective of 5\% (UNICEF 2020). Dar es Salaam, Tanzania's former capital and largest commercial centre, is divided into five 
administrative districts (Ilala, Kinondoni, Temeke, Ubungo, and Kigamboni), all of which are governed by municipal councils. The city has more public and private health facilities than any other region, all of which provide services following the country-wide PMTCT guidelines, which are primarily based on the WHO guidelines. Furthermore, the Management Development for Health (MDH) programme supports the majority of these facilities and the President's Emergency Plan for AIDS Relief (REPFAR), which provides technical support for HIV care and treatment (MDH 2015). The availability of this assistance makes these facilities more available to the majority of the population in need of basic health services, and it reflects the real-world conditions of Tanzanian health care facilities. In Dar es Salaam, there is no evidence of understanding of primary predictors for HIV MTCT. Furthermore, due to varying risks in different areas, determining the determinants of vertical HIV infections/transmissions is critical and must be addressed. As a result, this study aimed to determine the rates of transmissions and look into the risk factors for MTCT among HIVpositive infants born in Dar es Salaam, Tanzania.

\section{Materials and Methods \\ Study design, area and setting}

A health facility-based cross-sectional study design was employed using retrospective data collection. The study was conducted in Dar es Salaam, the former capital as well as the largest commercial city in Tanzania. It consists of five administrative districts (Ilala, Kinondoni, Temeke, Ubungo, and Kigamboni) and all are governed by municipal councils. The research involved public and private health care facilities that offer services according to the national PMTCT guidelines, adapted from the WHO guidelines.

\section{Study population and sample size}

The study population involved 21112 HIV-exposed infants aged $\leq 18$ months born to HIV-positive mothers enrolled in public and private health facilities providing PMTCT services from January 2016 to December 2019 in Dar es Salaam. The samples were comprised of 18705 infants who had a final confirmed HIV test result at 18 months of age. Because of missing data (HIV serostatus), transfer-out, or loss to follow-up, 2407 infants were excluded from the study. Out of the five administrative districts, four were studied (Ilala, Kinondoni, Temeke, and Ubungo).

\section{Variables considered}

The DNA/PCR test result was the dependent variable, while characteristics that might determine the risk of HIV infections, such as maternal age, duration on ART, marital status, adherence to ART, regimen type, maternal viral load, WHO clinical stage, regimen combination, sex of infant, infant age, age at DBS tested, infant ARV prophylaxis, infant cotrimoxazole prophylaxis, feeding practice, and district of residence were the independent variables.

\section{Data source and measurements}

The CTC2 database, which contains routinely obtained clinical data for HIV patients seeking treatment, was used to gather maternal information. The exposed newborn database was used to gather information on the children. Exposed infants were tested for HIV-1 infection using the Deoxyribonucleic Acid-Polymerase Chain Reaction (DNAPCR) assay at 6 weeks of age or at any time thereafter. The second PCR was taken to confirm the final infection status (positive or negative). Because maternal HIV antibodies diminish fast between 9 and 18 months of age, children between the ages of 9 and 18 months undergo a rapid HIV antibody test at their first health visit or after they stop breastfeeding. A DNA PCR test was used to confirm all positive results. When the infant was 4-6 weeks old, cotrimoxazole prophylaxis was routinely started. An Excel spreadsheet was used to enter and maintain 
the data, which was then checked for accuracy and transparency.

\section{Statistical analysis}

The current study focused on longitudinal survival analysis because the outcome variable of interest is the time until an event (HIV seropositive) occurs. The Cox proportional hazard regression model was used for both univariate (a single variable at a time) and multivariate (two or more variables) analyses. Continuous variables' values were expressed as medians and interquartile ranges, whereas categorical variables' values were expressed as percentages. To describe the research population in relation to key variables, frequency runs, cross tabulations, and summary statistics were used. The relationship between significant risk factors and MTCT was measured using hazard ratios with $95 \%$ confidence intervals. The reasoning for selecting the degree of significance (that is, $20 \%$ and $5 \%$ for univariate and multivariate analysis, respectively) was based on Hosmer et al. (2008) and Collett (2003) recommendations. Thus, all variables significant at a $p$-value $\leq 0.2$ in the univariate analysis were further entered into the final multivariate (adjusted) analysis, where adjusted hazard ratios were calculated. All variables with a $p$-value $<0.05$ were taken as independent risk factors for HIV infection serostatus in infants. The overall significance (at $p$-value $<0.05$ ) of the models was determined using three different tests (Likelihood ratio, Wald, and Score log-rank). The three tests are asymptotically equivalent and can be applied to any model with a likelihood function. All analyses were performed using the $\mathrm{R}$ software version 3.6.1 (2019-07-05).

\section{Validation of proportional hazard assumption}

The Cox proportional hazard model is based on the proportional hazard assumption, which states that the instantaneous risk of HIV infection in exposed infants in the care and control groups over the study period is constant (Guo 2010). The proportional hazard assumption can be violated, resulting in inaccurate and misleading estimates. A graphical approach, the use of a goodness of fit measure, and the use of a time-dependent variable in the Cox proportional hazard model are three general methods for evaluating the proportional hazard assumption (Kleinbaum and Klein 2012). The drawback of the graphical methods is that, when the covariate has more than two levels, Kaplan-Meier plots are not useful for discerning nonproportionality because the graphs are cluttered (Thernean and Grambsch 2000). As a result, the goodness of fit test was performed in this research, and the timedependent variable was used for model extension.

\section{The goodness of fit test}

The goodness of fit test between observed (data collected) and predicted (using the Cox model) survival function values was used to validate a proportional hazard assumption. The goodness of fit test gives a $p$-value $(p$ values $<0.05$ signify a violation of the proportional hazard assumption) and is, therefore, a more objective approach than visual methods (Kleinbaum and Klein 2012). The discrepancy between covariate variables observed in the real world and calculated using a Cox proportional hazard model for exposed infants who encounter an event of interest is a Schoenfeld residual test, which is a representative goodness of fit test. When the proportional hazard assumption is true, a straight horizontal line with zero slopes is predicted under the null hypothesis (i.e., the Schoenfeld residuals and event time have no relationship) (Schoenfeld 1982).

\section{Extended Cox model}

If the $\mathrm{PH}$ assumption is violated for one or more of the model's predictor variables, there are two choices to consider. The first choice is to stratify the Cox model according to the problematic dependent variable. In the stratification method, the effect of the covariate stratified on survival is absorbed into the baseline hazard functions in the stratified model; therefore, a hazard ratio for the covariate stratified on survival cannot be obtained (Kleinbaum and Klein 2005). The 
use of time-dependent variables is the second choice. The extended Cox model with a timedependent interaction term for the covariate is the best fit for this analysis since it quantifies the influence of the covariate on survival. As a result, when using this extended Cox model, a time function $\mathrm{g}(\mathrm{t})$ can take the form $\mathrm{g}(\mathrm{t})=0$, $\mathrm{g}(\mathrm{t})=\mathrm{t}, \mathrm{g}(\mathrm{t})=\log (\mathrm{t})$, or $\mathrm{g}(\mathrm{t})$ Heaviside function. This study took all the forms, and the best model was chosen using the Akaike information criterion (AIC). A lower AIC value indicates that the proposed model is well-suited to the data (Muhammad et al. 2019).

\section{Limitation of the study}

Since this study collected data from secondary sources, the information gathered may not have covered all the risk factors of MTCT. Not all maternal potential factors for vertical transmission were explored by the study, such as education level and employment status. Also, it was difficult to control for inconsistencies and missing values. The current study is based on urban areas and singleton births. This might also have introduced reporting bias. Therefore, generalization of the findings of this study may not be possible. Therefore, further research is needed to investigate additional risk factors for MTCT of HIV infection, especially in rural areas.

\section{Ethical consideration}

Ethical clearance approval was obtained from the University of Dar es Salaam Ethics Committee. Official permission letters were obtained from the regional administrative secretary (RAS) office, district administrative secretary (DAS) offices, and district medical offices in Dar es Salaam.

\section{Results and Discussion}

Of the 18705 samples, 586 (3.1\%) were HIV-positive. The prevalence of HIV was highest at $314(4.6 \%)$ among infants from Ilala. Male infants accounted for $49 \%$ of the 18705, while female infants accounted for $51 \%$. The majority of the exposed infants were aged 1-6 months, with a median age of 6 weeks, ranging from 6 to 9 weeks. More than half $(61.2 \%)$ of the infants had their DBS tested between 4 and 6 weeks, while only $38.8 \%$ were tested after 6 weeks. The mean age at which the DBS test was done was 4 weeks, ranging from 4 to 8 weeks. Furthermore, though 17210 (92\%) of the infants received ARV prophylaxis shortly after birth, $8 \%$ received no prophylaxis at all. Meanwhile, at enrolment, 17377 (92.9\%) exposed infants received cotrimoxazole prophylaxis therapy. In terms of HIV status, $586(3.1 \%)$ of the 18705 infants born to HIVpositive mothers were confirmed to be HIV positive, while 18119 (96.9\%) were negative. On the other hand, the majority of newborns $(92.5 \%)$ were put on exclusive breastfeeding (EBF), exclusive replacement feeding (ERF) (4.7\%), and mixed feeding (MF) (2.8\%). Table 1 shows that transmission rates were almost identical in male and female babies (3.1\% versus $3.2 \%$ ). Of the 18705 HIVpositive women, $53 \%$ were in the age group of 25-34 years, with a median age of 32 years (interquartile range (IQR) of 15-38 years) and were married or cohabiting (66\%). Furthermore, the majority $(63.3 \%)$ of mothers had received the ART treatment for longer than twelve months, and $96.3 \%$ adhered to it. Almost all mothers $(98.5 \%)$ were prescribed the first-line regimen, and more than threequarters $(86.1 \%)$ received an efavirenz (EFV)-based regimen combination during PMTCT intervention. Approximately $84.9 \%$ of HIV-positive mothers had viral suppression. Other baseline characteristics of infant/mother pairs are depicted in Table 1. 
Table 1: Sociodemographic and clinical characteristics of the study population

\begin{tabular}{|c|c|c|c|c|}
\hline \multicolumn{2}{|c|}{ Variables } & \multirow{2}{*}{$\begin{array}{l}\text { Total, N (\%) } \\
6548(35)\end{array}$} & \multicolumn{2}{|c|}{ HIV status } \\
\hline \multirow{4}{*}{$\begin{array}{l}\text { Maternal age } \\
(\text { yrs) }\end{array}$} & 15-24 vears & & $151(2.3)$ & $6397(97.7)$ \\
\hline & $25-34$ years & $9913(53)$ & $393(4)$ & $9520(96)$ \\
\hline & $35-49$ years & $2244(12)$ & $42(1.9)$ & $2202(98.1)$ \\
\hline & $\begin{array}{l}\text { Median (IQR): } 32 \\
\text { years (15-38 years) }\end{array}$ & & & \\
\hline \multirow[t]{3}{*}{ Marital status } & Married/cohabiting & $12322(66)$ & $387(3.1)$ & $11935(96.9)$ \\
\hline & Single (unmarried) & $5411(29)$ & $171(3.2)$ & $5240(96.8)$ \\
\hline & Widowed/Divorced & $936(5)$ & $28(3)$ & $908(97)$ \\
\hline \multirow{2}{*}{$\begin{array}{l}\text { Duration on } \\
\text { ART } \\
\end{array}$} & $<=12$ months & $6867(36.7)$ & $289(4.2)$ & $6578(95.8)$ \\
\hline & $>12$ months & $11838(63.3)$ & $297(2.5)$ & $11541(97.5)$ \\
\hline \multirow{2}{*}{$\begin{array}{l}\text { Adherence to } \\
\text { ART }\end{array}$} & Good & $18000(96.3)$ & $565(3.1)$ & $17435(96.9)$ \\
\hline & Poor & $686(3.7)$ & $21(3)$ & $665(96.9)$ \\
\hline \multirow[t]{2}{*}{ Regimen type } & $1^{\text {st }}$ line regimen & $18422(98.5)$ & $580(3.1)$ & $17842(96.9)$ \\
\hline & $2^{\text {nd }}$ line regimen & $283(1.5)$ & $6(2.1)$ & $277(97.9)$ \\
\hline \multirow{2}{*}{$\begin{array}{l}\text { Maternal viral } \\
\text { load }\end{array}$} & Suppressed & $15825(84.9)$ & $216(1.4)$ & $15609(98.6)$ \\
\hline & Not suppressed & $2824(15.1)$ & $370(13.1)$ & $2454(86.9)$ \\
\hline \multirow{2}{*}{$\begin{array}{l}\text { WHO clinical } \\
\text { stage }\end{array}$} & Stages 1-2 & $17583(94)$ & $481(2.7)$ & $17102(97.3)$ \\
\hline & Stages 3-4 & $1122(6)$ & $105(9.4)$ & $1017(90.6)$ \\
\hline \multirow{3}{*}{$\begin{array}{l}\text { Regimen } \\
\text { combination }\end{array}$} & EFV based & $16102(86.1)$ & $512(3.2)$ & $15590(96.8)$ \\
\hline & NVP based & $2320(12.4)$ & $68(2.9)$ & $2252(97.1)$ \\
\hline & Others & $283(1.5)$ & $6(2.1)$ & $277(97.9)$ \\
\hline \multirow[t]{2}{*}{ Sex of infant } & Male & $9165(49)$ & $284(3.1)$ & $8881(96.9)$ \\
\hline & Female & $9540(51)$ & $302(3.2)$ & $9238(96.8)$ \\
\hline \multirow[t]{4}{*}{ Infant age } & $1-6$ months & $15852(84.7)$ & $457(2.9)$ & $15395(97.1)$ \\
\hline & $7-12$ months & $1502(8.0)$ & $87(5.8)$ & 1415 (94.2) \\
\hline & 13-18 months & $1351(7.0)$ & $42(3.1)$ & $1309(96.9)$ \\
\hline & $\begin{array}{l}\text { Median (IQR): } 1 \\
\text { month (1-2 months) }\end{array}$ & & & \\
\hline \multirow{3}{*}{$\begin{array}{l}\text { Age at DBS } \\
\text { tested }\end{array}$} & $<=6$ weeks & $11440(61.2)$ & $334(2.9)$ & $11106(97.1)$ \\
\hline & $>6$ weeks & $7265(38.8)$ & $252(3.5)$ & $7013(96.5)$ \\
\hline & $\begin{array}{l}\text { Median (IQR): } \\
\text { 6weeks (6-9 weeks) }\end{array}$ & & & \\
\hline \multirow{2}{*}{$\begin{array}{l}\text { Infant ARV } \\
\text { prophylaxis }\end{array}$} & Received & $17210(92)$ & $294(1.7)$ & $16916(98.3)$ \\
\hline & Not received & $1495(8)$ & $292(19.5)$ & $1203(80.5)$ \\
\hline \multirow{2}{*}{$\begin{array}{l}\text { Infant } \\
\text { cotrimoxazole }\end{array}$} & Received & $17377(92.9)$ & $533(3.1)$ & $16844(96.9)$ \\
\hline & Not received & $1328(7.1)$ & $53(4)$ & $1275(96)$ \\
\hline \multirow[t]{3}{*}{$\begin{array}{l}\text { Feeding } \\
\text { practice }\end{array}$} & $\begin{array}{l}\text { Exclusive } \\
\text { breastfeeding (EBF) }\end{array}$ & $17299(92.5)$ & $452(2.6)$ & $16847(97.4)$ \\
\hline & $\begin{array}{l}\text { Exclusive replacement } \\
\text { feeding (ERF) }\end{array}$ & $881(4.7)$ & $33(3.7)$ & $848(96.3)$ \\
\hline & Mixed feeding (MF) & $525(2.8)$ & $100(19)$ & $425(81)$ \\
\hline \multirow{4}{*}{$\begin{array}{l}\text { District of } \\
\text { residence }\end{array}$} & Ilala & $6786(36.3)$ & $314(4.6)$ & $6472(95.4)$ \\
\hline & Temeke & $5003(26.7)$ & $84(1.7)$ & $4919(98.3)$ \\
\hline & Kinondoni & $4006(21.4)$ & $109(2.7)$ & $3897(97.3)$ \\
\hline & Ubungo & $2910(15.6)$ & $79(2.7)$ & $2831(97.3)$ \\
\hline
\end{tabular}

* Numbers do not always add up to total because of missing data. 
The association between survival time and the explanatory variables was investigated using univariate and multivariate analyses. All variables with a $p$-value $<0.2$ in the univariate (crude) analysis were included in the multivariate (adjusted) analysis, with the exception of infant age $(p$-value $=0.876$ and 0.627 ) and sex of infant ( $p$-value $=0.899$ ). The Breslow method was used to estimate the parameters of the Cox proportional hazard model (Table 2).

Table 2: Cox proportional hazard model parameter estimation with Breslow method

\begin{tabular}{|c|c|c|c|c|c|}
\hline \multicolumn{2}{|c|}{ Variables } & \multicolumn{2}{|c|}{ Univariate Analysis } & \multicolumn{2}{|c|}{ Multivariate Analysis } \\
\hline & & $\begin{array}{c}\text { Crude HR }(95 \% \\
\text { CI) }\end{array}$ & $P$-value & $\begin{array}{l}\text { Adjusted HR } \\
\text { (95\% CI })\end{array}$ & $P$-value \\
\hline \multirow[t]{3}{*}{ Maternal age } & $15-24$ yrs & $0.63(0.52-0.76)$ & $<0.001$ & $0.82(0.63-1.07)$ & 0.144 \\
\hline & $25-34$ yrs & 1.00 & - & 1.00 & - \\
\hline & $35-49$ yrs & $0.55(0.40-0.76)$ & $<0.001$ & $0.19(0.12-0.31)$ & $<0.001$ \\
\hline \multirow[t]{3}{*}{ Marital status } & Married/ cohabiting & 1.00 & - & 1.00 & - \\
\hline & Single (unmarried) & $0.94(0.79-1.13)$ & 0.503 & $0.50(0.40-0.64)$ & $<0.001$ \\
\hline & Widowed/ Divorced & $0.95(0.65-1.39)$ & 0.790 & $0.98(0.65-1.47)$ & 0.918 \\
\hline \multirow{2}{*}{$\begin{array}{l}\text { Duration on } \\
\text { ART }\end{array}$} & $<=12$ months & $1.60(1.36-1.88)$ & $<0.001$ & $0.47(0.38-0.58)$ & $<0.001$ \\
\hline & $>12$ months & 1.00 & - & 1.00 & - \\
\hline \multirow{2}{*}{$\begin{array}{l}\text { Adherence to } \\
\text { ART }\end{array}$} & Good & 1.00 & - & 1.00 & - \\
\hline & Poor & $1.46(0.94-2.26)$ & 0.089 & $1.05(0.66-1.65)$ & 0.846 \\
\hline \multirow[t]{2}{*}{ Regimen type } & $1^{\text {st }}$ line regimen & 1.00 & 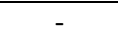 & 1.00 & \\
\hline & $2^{\text {nd }}$ line regimen & $1.80(0.80-4.04)$ & 0.157 & $1.52(0.65-3.55)$ & 0.333 \\
\hline \multirow{3}{*}{$\begin{array}{l}\text { Regimen } \\
\text { combination }\end{array}$} & EFV based & 1.00 & - & 1.00 & - \\
\hline & NVP based & $0.97(0.75-1.25)$ & 0.792 & $1.10(0.83-1.47)$ & 0.505 \\
\hline & Others & $1.79(0.80-4.02)$ & 0.160 & $0.72(0.52-1.01)$ & 0.053 \\
\hline \multirow{2}{*}{$\begin{array}{l}\text { Maternal viral } \\
\text { load }\end{array}$} & Suppressed & 1.00 & - & 1.00 & - \\
\hline & Not suppressed & $\begin{array}{l}11.81(9.94- \\
14.02)\end{array}$ & $<0.001$ & $\begin{array}{c}7.85(6.14- \\
10.03) \\
\end{array}$ & $<0.001$ \\
\hline \multirow{2}{*}{$\begin{array}{l}\text { WHO clinical } \\
\text { stage }\end{array}$} & Stages 1-2 & 1.00 & - & 1.00 & - \\
\hline & Stages 3-4 & $3.30(2.67-4.08)$ & $<0.001$ & $1.55(1.23-1.95)$ & $<0.001$ \\
\hline \multirow[t]{2}{*}{ Sex of infant } & Male & $1.011(0.86-1.19)$ & 0.899 & $* *$ & \\
\hline & Female & 1.00 & - & & \\
\hline \multirow[t]{3}{*}{ Infant age } & $1-6$ months & 1.00 & - & ** & \\
\hline & $7-12$ months & $0.98(0.74-1.29)$ & 0.876 & & \\
\hline & $13-18$ months & $0.79(0.31-2.01)$ & 0.627 & & \\
\hline \multirow{2}{*}{$\begin{array}{l}\text { Age at DBS } \\
\text { tested }\end{array}$} & $<=6$ weeks & 1.00 & - & 1.00 & - \\
\hline & $>6$ weeks & $0.02(0.01-0.02)$ & $<0.001$ & $0.09(0.07-0.13)$ & $<0.001$ \\
\hline \multirow{2}{*}{$\begin{array}{l}\text { Infant ARV } \\
\text { prophylaxis }\end{array}$} & Received & 1.00 & - & 1.00 & - \\
\hline & Not received & $9.93(8.45-11.68)$ & $<0.001$ & $3.54(2.89-4.34)$ & $<0.001$ \\
\hline \multirow{2}{*}{$\begin{array}{l}\text { Infant } \\
\text { cotrimoxazole }\end{array}$} & Received & 1.00 & - & 1.00 & - \\
\hline & Not received & $0.54(0.40-0.73)$ & $<0.001$ & $1.16(0.85-1.58)$ & 0.362 \\
\hline \multirow[t]{3}{*}{$\begin{array}{l}\text { Feeding } \\
\text { practice }\end{array}$} & $\begin{array}{l}\text { Exclusive } \\
\text { replacement feeding }\end{array}$ & 1.00 & - & 1.00 & - \\
\hline & $\begin{array}{l}\text { Exclusive breast } \\
\text { feeding }\end{array}$ & $0.84(0.59-1.20)$ & $<0.333$ & $0.20(0.13-0.29)$ & $<0.001$ \\
\hline & Mixed feeding & $6.99(4.72-10.36)$ & $<0.001$ & $4.35(2.83-6.69)$ & $<0.001$ \\
\hline \multirow{4}{*}{$\begin{array}{l}\text { District of } \\
\text { residence }\end{array}$} & Ilala & 1.00 & - & 1.00 & - \\
\hline & Temeke & $0.37(0.29-0.47)$ & $<0.001$ & $0.38(0.28-0.51)$ & $<0.001$ \\
\hline & Kinondoni & $0.70(0.56-0.87)$ & $<0.001$ & $0.45(0.34-0.59)$ & $<0.001$ \\
\hline & Ubungo & $0.58(0.46-0.75)$ & $<0.001$ & $0.51(0.38-0.70)$ & $<0.001$ \\
\hline
\end{tabular}


The goodness-of-fit test was used in this analysis to test the proportional hazard assumption of the Cox proportional hazard model (Schoenfeld residual).

Table 3 shows that the proportional hazard assumption is met when the duration of ART, cotrimoxazole prophylaxis, regimen type, regimen combination, adherence to ART, WHO clinical stage, and maternal viral load variables all have $p$-values $>0.05$. However, the variables infant ARV prophylaxis, feeding practice, age at DBS tested, marital status, maternal age group, and district of residence all have $p$-values $<0.05$, indicating that the proportional hazard assumption has been violated.

As depicted in Figure 1, the curves are not horizontal; suggesting that the Cox proportional hazard assumption was violated.

Table 3: Testing PH Assumption

\begin{tabular}{lccc}
\hline Variable & Chisq & df & $\boldsymbol{p}$-value \\
\hline Duration on ART & 2.903 & 1 & 0.088 \\
Infant ARV prophylaxis & 18.262 & 1 & $<0.001$ \\
Infant cotrimoxazole & 3.323 & 1 & 0.068 \\
Feeding practice & 25.001 & 2 & $<0.001$ \\
Age at DBS tested & 14.143 & 1 & $<0.001$ \\
Regimen type & 0.716 & 1 & 0.398 \\
Regimen combination & 3.708 & 2 & 0.054 \\
Adherence to ART & 0.862 & 1 & 0.353 \\
WHO clinical stage & 0.234 & 1 & 0.629 \\
Maternal viral load & 0.776 & 1 & 0.378 \\
Marital status & 10.356 & 2 & 0.006 \\
Maternal age group & 9.314 & 2 & 0.009 \\
District of residence & 8.271 & 3 & 0.041 \\
GLOBAL & 114.371 & 18 & $<0.001$ \\
\hline
\end{tabular}



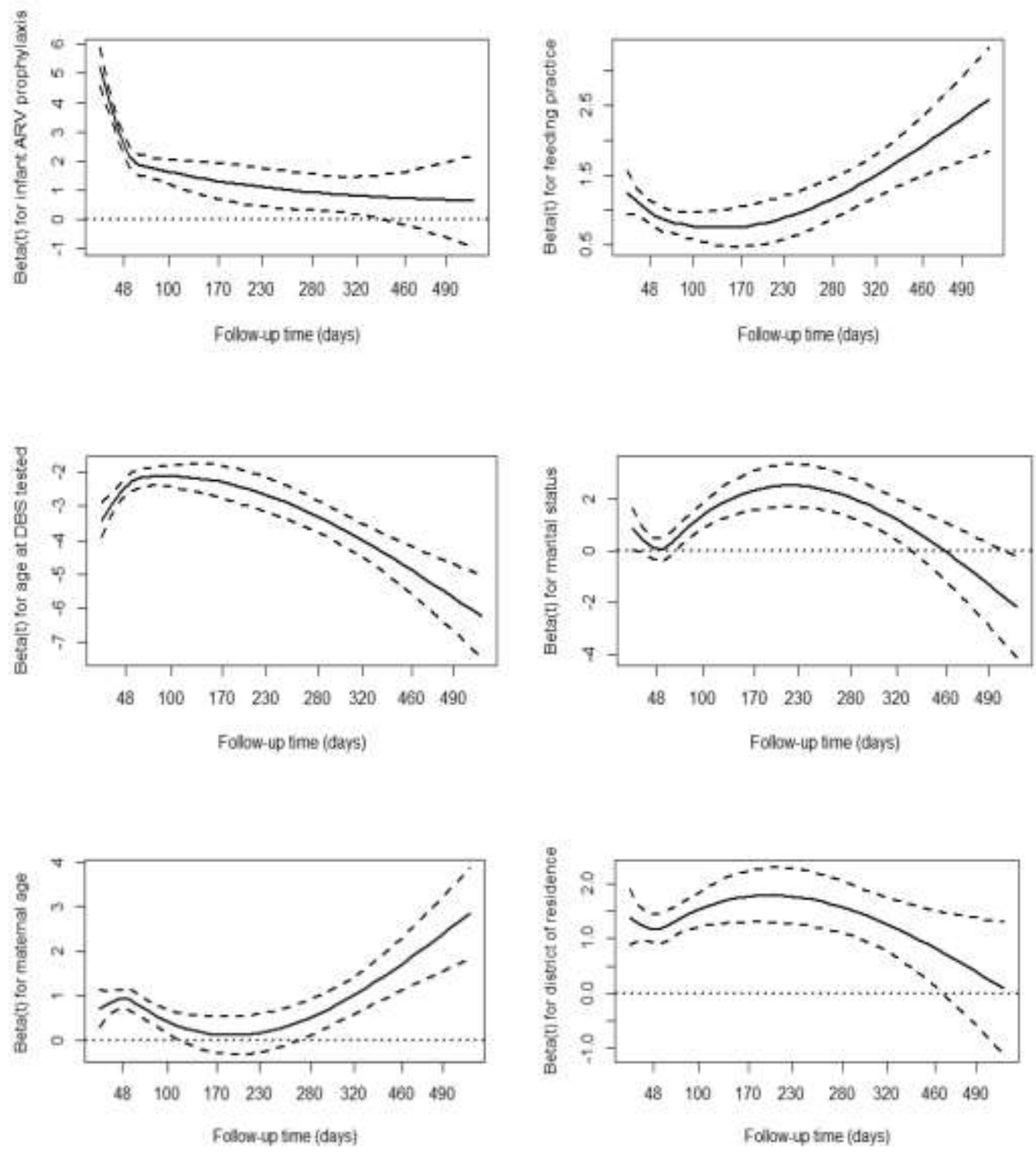

Figure 1: Schoenfeld residual graphs of infant ARV prophylaxis, feeding practice, age at DBS tested, marital status, maternal age, and district of residence. 
Table 4: Extended Cox PH model parameter estimation for $\mathrm{g}(\mathrm{t})=\log (\mathrm{t})$ with Breslow method

\begin{tabular}{|c|c|c|c|c|}
\hline & ariables & Adjusted HR & $95 \% \mathrm{CI}$ & $P$-value \\
\hline Maternal age & $15-24$ yrs & 0.63 & $0.30-1.33$ & 0.227 \\
\hline & $25-34$ yrs & 1.00 & - & - \\
\hline & $35-49$ yrs & 0.47 & $0.29-0.75$ & $<0.001$ \\
\hline Marital status & Married/cohabiting & 1.00 & - & - \\
\hline & Single (unmarried) & 0.47 & $0.23-0.95$ & 0.036 \\
\hline & Widowed/Divorced & 1.06 & $0.35-3.24$ & 0.921 \\
\hline Duration on & $<=12$ months & 0.55 & $0.45-0.67$ & $<0.001$ \\
\hline ART & $>12$ months & 1.00 & - & - \\
\hline Adherence to & Good & 1.00 & - & - \\
\hline ART & Poor & 0.21 & $0.03-1.45$ & 0.113 \\
\hline Regimen type & $1^{\text {st }}$ line regimen & 1.00 & - & \\
\hline & $2^{\text {nd }}$ line regimen & 1.07 & $0.16-7.32$ & 0.945 \\
\hline Regimen & EFV based & 1.00 & - & - \\
\hline combination & NVP based & 1.42 & $0.31-6.53$ & 0.651 \\
\hline & Others & 0.05 & $0.01-0.27$ & 0.053 \\
\hline Maternal viral & Suppressed & 1.00 & - & - \\
\hline load & Not suppressed & 6.26 & $4.91-7.97$ & $<0.001$ \\
\hline WHO clinical & Stages $1-2$ & 1.00 & - & - \\
\hline stage & Stages 3-4 & 1.79 & $1.44-2.23$ & $<0.001$ \\
\hline Age at DBS & $<=6$ weeks & 1.00 & - & - \\
\hline tested & $>6$ weeks & 0.09 & $0.04-0.18$ & $<0.001$ \\
\hline Infant ARV & Received & 1.00 & - & - \\
\hline prophylaxis & Not received & 2.39 & $1.75-3.26$ & $<0.001$ \\
\hline Infant & Received & 1.00 & - & - \\
\hline cotrimoxazole & Not received & 1.02 & $0.74-1.40$ & 0.904 \\
\hline Feeding practice & $\begin{array}{l}\text { Exclusive replacement } \\
\text { feeding }\end{array}$ & 1.00 & - & - \\
\hline & Exclusive breast feeding & 0.32 & $0.17-0.60$ & $<0.001$ \\
\hline & Mixed feeding & 4.09 & $1.80-9.31$ & $<0.001$ \\
\hline District of & Ilala & 1.00 & - & - \\
\hline residence & Temeke & 2.29 & $0.15-0.54$ & $<0.001$ \\
\hline & Kinondoni & 0.42 & $0.28-0.63$ & $<0.001$ \\
\hline & Ubungo & 0.51 & $0.33-0.77$ & 0.002 \\
\hline Maternal age & $15-24$ years & 0.18 & $0.01-0.32$ & $<0.001$ \\
\hline$g(t)$ & $25-34$ years & 1.00 & - & - \\
\hline & $35-49$ years & 2.14 & $0.81-5.67$ & 0.127 \\
\hline Marital status & Married/cohabiting & 1.00 & - & - \\
\hline $\mathbf{g}(\mathbf{t})$ & Single (unmarried) & 1.54 & $1.06-2.22$ & 0.023 \\
\hline & Widowed/Divorced & 0.31 & $0.00-5.32$ & 0.655 \\
\hline Age at DBS & $<=6$ weeks & 1.00 & - & - \\
\hline tested $g(t)$ & $>6$ weeks & 0.19 & $0.14-0.27$ & $<0.001$ \\
\hline Infant ARV & Received & 1.00 & - & - \\
\hline prophylaxis g(t) & Not received & 1.18 & $0.85-1.63$ & 0.326 \\
\hline $\begin{array}{l}\text { Feeding practice } \\
g(t)\end{array}$ & $\begin{array}{l}\text { Exclusive replacement } \\
\text { feeding }\end{array}$ & 1.00 & - & - \\
\hline & Exclusive breast feeding & 1.11 & $0.48-2.57$ & 0.813 \\
\hline & Mixed feeding & 4.42 & $1.81-10.82$ & 0.001 \\
\hline District of & Ilala & 1.00 & - & - \\
\hline residence $g(t)$ & Temeke & 0.53 & $0.26-1.06$ & 0.074 \\
\hline & Kinondoni & 0.18 & $0.11-0.29$ & $<0.001$ \\
\hline & Ubungo & 0.76 & $0.31-1.90$ & 0.560 \\
\hline
\end{tabular}

All the three alternatives (Likelihood ratio, Wald, and Score log-rank) tests revealed the overall significance (at $p$-value $<0.001$ ) of the extended Cox models, as shown in Table 5. 
Table 5: Testing a global null hypothesis

\begin{tabular}{lccccc}
\hline Test & \multicolumn{5}{c}{ Chi-square } \\
\cline { 2 - 5 } & $\begin{array}{c}\text { Cox PH } \\
\text { Model }\end{array}$ & $\begin{array}{c}\text { Ext. Cox PH } \\
\mathrm{g}(\mathrm{t})=\mathrm{t}\end{array}$ & $\begin{array}{c}\text { Ext. Cox PH } \\
\mathrm{g}(\mathrm{t})=\log (\mathrm{t})\end{array}$ & $\begin{array}{c}\text { Ext. Cox PH } \\
\text { Heaviside } \\
\text { function }\end{array}$ & $P$-value \\
\hline Likelihood & 2114 & 1931 & 2536 & 2274 & $<0.001$ \\
Wald & 2283 & 1804 & 2566 & 2248 & $<0.001$ \\
Score (logrank) & 4474 & 3884 & 7379 & 4711 & $<0.001$ \\
\hline
\end{tabular}

Table 6: Testing Goodness of Fit (GOF)

\begin{tabular}{|c|c|c|c|c|}
\hline & $\begin{array}{ll}\text { Cox } & \text { PH } \\
\text { Model } & \\
\end{array}$ & $\begin{array}{l}\text { Ext. Cox Model } \\
g(t)=t\end{array}$ & $\begin{array}{l}\text { Ext. Cox Model } \\
g(t)=\log (t)\end{array}$ & $\begin{array}{l}\text { Ext. Cox Model } \\
\text { Heaviside function }\end{array}$ \\
\hline $\begin{array}{l}\text { Log } \\
\text { Likelihood }\end{array}$ & -4150.426 & -4037.379 & -3939.658 & -4070.351 \\
\hline $\begin{array}{l}-2 \log \\
\text { Likelihood }\end{array}$ & 8302.086 & 8074.758 & 7879.316 & 8140.702 \\
\hline AIC & 8300.852 & 8166.758 & 7956.316 & 8165.702 \\
\hline
\end{tabular}

The Cox proportional hazard model was expanded to account for covariates that violated the Cox assumption. In this study, the variables infant ARV prophylaxis, feeding practice, age at DBS tested, marital status, maternal age group, and district of residence interacted with time function $\mathrm{g}(\mathrm{t}), \mathrm{g}(\mathrm{t})=\log (\mathrm{t})$ and Heaviside function. Therefore, based on Table 5 and the Akaike Information Criterion (Table 6), the Extended Cox Model with $\mathrm{g}(\mathrm{t})=\log (\mathrm{t})$ was the best model (Table 4).

Accordingly, babies born to HIV-positive mothers with an unsuppressed viral load were 6 times more likely $(\mathrm{aHR}=6.26,95 \% \mathrm{CI}$ : 4.91-7.97, $P<0.001)$ to transmit the virus to their children compared to mothers with a lower (suppressed) viral load. Similar findings were published by Bucagu et al. (2013) and Novitsky and Essex (2012). The level of HIV RNA in maternal plasma remains the major biological predictor of both early and late mother-to-child transmission of the virus. Total viral suppression provides the most protective effect against mother-to-child transmission of HIV (Joao et al. 2012). In terms of marital status, exposed infants born to HIV-positive mothers who were married or cohabiting were $53 \%$ less likely to contract HIV than those born to single (unmarried) mothers (aHR $=0.47,95 \%$ CI: $0.23-0.95, P=$ 0.036). Furthermore, infants born from HIVpositive mothers who were in WHO clinical stages 3-4 had a twofold higher risk of acquiring HIV infections compared to their counterparts $(\mathrm{aHR}=1.79,95 \%$ CI: $1.44-2.25$, $P<0.001)$. As compared to their counterparts, HIV-positive women who had been on ART treatments for more than twelve months were $45 \%$ less likely to transmit HIV infections to their newborns $(\mathrm{aHR}=0.55$, 95\% CI: $0.45-0.67, P<0.001)$. This observation might be attributed to the effects of the treatments on the viral load and subsequent transmissions. This finding is consistent with other studies (Shargie et al. 2014, Berhan et al. 2014). As a result, the risk of HIV transmission was two times higher for exposed infants who did not undergo ARV prophylaxis immediately after birth (aHR = 2.39, 95\% CI: $1.75-3.26, P<0.001)$. This finding is in line with previous research from low-income countries (Mirkuzie et al. 2010, Wudineh and Damtew 2016). This is because the drugs' effects appear to suppress and reduce the viral load in the child's blood. Infants who got DBS tests at the age of 6 weeks had a 91.1\% lower chance of contracting HIV from their HIV-positive mothers than their counterparts $(\mathrm{aHR}=0.09$, 95\% CI: $0.04-0.18, \quad P<0.001)$. This observation is supported by research from other African countries (Mirkuzie et al. 2010, Berhan et al. 2014). This observation may be due to the fact that the older the infants were 
when they got into health facilities for diagnosis, the more likely they were likely to be exposed to HIV infections due to the longer time of breast feeding. In this study, exposed infants born to mothers in the age range of 25-34 years were $53 \%$ (aHR $=0.47$, 95\% CI: $0.29-0.75, P<0.001)$ less likely to have positive DNA/PCR test results as compared to infants born to mothers in the age group of 35-49 years. In fact, this was in harmony with the results of a study done in Ethiopia (Berhan et al. 2014). Infants on exclusive replacement feeding were $68 \%$ $($ aHR $=0.32,95 \%$ CI: $0.17-0.60, P<0.001)$ less likely to be infected with HIV than exposed infants who were exclusively breastfed. However, when compared to exclusive replacement feeding (ERF), infants on mixed feeding (MF), they were 4 times (aHR $=4.09,95 \%$ CI: $1.08-9.31, P<0.001)$ more likely to contract HIV from their mothers. Similar studies from resourcelimited countries have also reported mixed feeding as an independent predictor of HIV transmissions (Koye and Zeleke 2013, Wudineh and Damtew 2016). Mixed feeding can cause gastrointestinal infections and laceration, which can cause the mucosal barrier to break down, allowing viruses to enter the bloodstream (Wudineh and Damtew 2016). In addition, HIV-positive mothers from Ilala had a lower risk of infecting their babies as compared to mothers from Temeke $($ aHR $=0.29,95 \%$ CI: $0.15-0.54, P<0.001)$, Kinondoni $(\mathrm{aHR}=0.42,95 \% \mathrm{CI}$ : $0.28-0.63$, $P<0.001$ ), and Ubungo ( $\mathrm{aHR}=0.51,95 \%$ CI: $0.33-0.77, P=0.002)$.

\section{Conclusion}

The extended Cox proportional hazards model was used to model the survival time for exposed infants born to HIV-positive mothers. To resolve the non-proportionality assumption, the extended Cox regression model was fitted. To find the best extended Cox model with $g(t)=\log (t)$, the Akaike information criterion (AIC) was used. Based on hazard ratios, the interpretation of the results identified infants taking no ARV prophylaxis right at birth, WHO clinical stages 3-4, no suppressed maternal viral load, and mixed feeding practice as statistically significant and independently risk factors associated with vertical HIV transmission. Finally, these results can be valuable information for all health stakeholders interested in enhancing PMTCT programme effectiveness.

\section{Conflict of interests}

The authors declare that they have no conflicting interests.

\section{Acknowledgements}

The authors are grateful to all the Dar es Salaam's District Medical Offices for their assistance in gathering data, as well as the Dar es Salaam Institute of Technology (DIT) for its financial support.

\section{References}

Berhan Z, Abebe F, Gedefaw M, Tesfa M, Assefa M and Tafere Y 2014 Risk of HIV and association factors among infants born to HIV positive women in Amhara region, Ethiopia: a facility based retrospective study. MBC Res. Notes 7: 876.

Bucagu M, Bizimana Jde D, Muganda J and Humblet CP 2013 Socio-economic, clinical and biological risk factors for mother-to-child transmission of HIV-1 in Muhima health centre (Rwanda): a prospective cohort study. Arch Public Health 71(1): 4.

Buchanan AM, Dow DE, Massambu CG, Nyombi B, Shayo A, Musoke R, Feng S, Bartlett JA, Cunningham CK and Schimana W 2014 Progress in the prevention of mother to child transmission of HIV in three regions of Tanzania: a retrospective analysis. PLoS One. 9(2): e88679.

Chikhungu LC, Bispo S, Rollins N, Siegfried $\mathrm{N}$ and Newell ML 2016 HIV-free survival at 12-24 months in breastfed infants of HIV-infected women on antiretroviral treatment. Trop. Med. Int. Health 21(7): 820-828.

Collett D 2003 Modelling survival data in medical research. $2^{\text {nd }}$ ed., Chapman and Hall/CRC, London. 
De Cock KM, Fowler MG, Mercier E, de Vincenzi I, Saba J, Hoff E, Alnwick DJ, Rogers M and Shaffer N 2000 Prevention of mother-to-child HIV transmission in resource-poor countries: translating research into policy and practice. Jama 283 (9): 1175-1182.

Wudineh F and Damtew B 2016 Mother-tochild transmission of HIV infection and its determinants among exposed infants on care and follow-up in Dire Dawa City, Eastern Ethiopia. AIDS Res Treat. 2016: 3262746.

Giaquinto C, Rampon O and De Rossi A 2006 Antiretroviral therapy for prevention of mother-to-child HIV transmission: focus on single-dose nevirapine. Clin. Drug Investig. 26(11): 611-627.

Guo S 2010 Survival analysis. Oxford University Press, New York.

Hosmer DW, Lemeshow S and May S 2008 Applied survival analysis: regression modeling of time to event data. John Wiley and Sons, New York.

Joao EC, Gouvêa MI, Menezes JA, Sidi LC, Cruz ML, Berardo PT, Ceci L, Cardoso CA, Teixeira Mde L, Calvet GA and Matos HJ 2012 Factors associated with viral load suppression in HIV-infected pregnant women in Rio de Janeiro, Brazil. Int. J. STD AIDS 23(1): 44-47.

Kleinbaum DG and Klein M 2005 Survival analysis. A self-learning text. $2^{\text {nd }}$ ed, Springer-Verlag, New York.

Kleinbaum DG and Klein M 2012 Survival analysis. A self-learning text, $3^{\text {rd }}$ ed, Springer-Verlag, New York.

Koye DN and Zeleke BM 2013 Mother-tochild transmission of HIV and its predictors among HIV-exposed infants at a PMTCT clinic in northwest Ethiopia. BMC Public Health 13(1): 398.

Management and Development for Health (MDH) 2015. Maternal health. Available from http://www.mdh-tz.org/

Ministry of Health, Community Development, Gender, Elderly, and Children 2019 Tanzania HIV impact survey: THIS 2016-2017 final report, p68. [pdf]
Mirambo MM, Simon C, Kajura A, Kidenya B, Majigo M, and Mshana SE 2015 Reduction of HIV transmission rates from mother to child in the era of antiretroviral therapy in the Lake Victoria zone, Tanzania. Tanz. J. Health Res. 17(3).

Mirkuzie AH, Hinderaker SG, and Mørkve O 2010 Promising outcomes of a national programme for the prevention of motherto-child HIV transmission in Addis Ababa: a retrospective study. BMC Health Serv Res. 10: 267.

Muhammad M, Gunawan and Yuwaningsih DA 2019 Estimating survival time of Dengue Haemorrhagic fever using extended Cox model. J. Phys.: Conf. Ser. 1188(2019)012017.

Newell ML 2001 Prevention of mother-tochild transmission of HIV: challenges for the current decade. Bull. World Health Organ. 79(12): 1138-44.

Novitsky V and Essex M 2012 Using HIV viral load to guide treatment-forprevention interventions. Curr. Opin. HIV AIDS 7(2): 117-124.

Schoenfeld D 1982 Partial residuals for the proportional hazard regression model. Biometrika 69(1): 239-241.

Shargie MB, Eek F and Abaychew A 2014 Prophylactic treatment uptake and compliance with recommended follow up among HIV exposed infants: a retrospective study in Addis Ababa, Ethiopia. BMC Res. Notes 4: 563.

Sidibé M and Singh PK 2016 Thailand eliminates mother-to-child transmission of HIV and syphilis. Lancet 387(10037): 2488-2489.

Thernean TM and Grambsch PM 2000 Modeling survival data: extending the Cox model. Springer, New York, NY.

UNAIDS 2013 Progress report on the global plan: towards the elimination of new HIV infections among children by 2015 and keeping their mothers alive. Available from

https://www.unaids.org/en/resources/docu ments/2013/20130625_progress_global_pl an_en.pdf

UNAIDS 2018 UNAIDS Data 2018. Available from 
https://www.unaids.org/en/resources/docu ments/2018/unaids-data-2018

UNAIDS 2020a Country progress reportUnited Republic of Tanzania. https://www.unaids.org/sites/default/files/ country/documents/TZA_2020_countryre port.pdf

UNAIDS 2020b UNAIDS data. Available from

https://www.unaids.org/en/resources/docu ments/2020/unaids-data

UNICEF 2019 The mother of all prevention. Available from https://www.unicef.org/tanzania/stories/m other-all-prevention

UNICEF 2020 What-we-do. Available from https://www.unicef.org/tanzania/what-wedo/hiv-aids

WHO 2016 Consolidated guidelines on the use of antiretroviral drugs for treating and preventing HIV infection: recommendations for a public health approach, $2^{\text {nd }}$ ed. Geneva. World Health Organization. 